\title{
The Narcissistic Grandiosity Scale; Psychometric Evaluation of the Iranian Version
}

\author{
Sara Hoseingholizade ${ }^{1},{ }^{*}$ Mohammad Effatpanah², Nazanin Mousavi ${ }^{1}$, Mandana Piryaei ${ }^{1}$, Ali \\ Mohammad Mousavi ${ }^{1}$ \\ ${ }^{*}$ Corresponding Author \\ Email Addresses: hoseingholizade@ut.ac.ir (S. Hoseingholizade), \\ m-effatpanah@tums.ac.ir (M. Effatpanah) \\ Under review at Iranian Journal of Psychiatry and Behavioral Sciences
}

\section{Abstract}

Background: Recently, the rising number of research has led to improved measures for assessing narcissism. Aside from all the measures assessing the trait-level of grandiose narcissism, the Narcissistic Grandiosity Scale (NGS) measures withinperson dynamics of grandiose narcissism in both trait- and state-level and makes it possible to evaluate the grandiosity's oscillations over time.

Methods: This study aims to evaluate the psychometric properties of the Persian version of NGS and address the most suitable form out of the existing five versions. The sample consists of 426 participants $(59.06 \%$ were female and $40.03 \%$ were married). The Cronbach's Alpha, test-retest coefficient, and confirmatory factor analysis (CFA) were reliability assessments. For the convergent and discriminant validity, the Rosenberg Self-Esteem Scale (RSES), Brief Pathological Narcissism Inventory -Grandiosity (B-PNI-G) and Vulnerability (B-PNI-V)- were administered aside from NGS.

Results: The pilot study (45 participants) showed high consistency and fluent translation. For the total score, Cronbach's alpha was 0.915 , and alphas were found in the range of 0.905-0.918 for items. The test-retest reliability coefficient was 0.904 . The CFA results were as follows; the 6-item version was the most suitable one (CFI= 0.970, TLI=0.950, RMSEA $=0.076$, and SRMR=0.037). Its Pearson coefficient with RSES was 0.568, with the B-PNI-G was 0.200, and with B-PNI-V was -0.127 (all were significant).

Conclusion: The results indicate that the 6-item version of NGS can serve as the most suitable tool for assessing narcissistic grandiosity among non-clinical samples among Iranians.

\footnotetext{
1. Department of Psychology, Faculty of Social Sciences, Imam Khomeini International University, Qazvin, Iran 2. MD \& MPH, Associated Professor of Child \& Adolescent Psychiatry, Pediatric Department, School of Medicine, Imam Khomeini Hospital, Tehran University of Medical Sciences, Tehran, Iran
} 
Keywords: Narcissistic Grandiosity Scale, Narcissism, Grandiosity, Psychometric Properties, NGS

\section{INTRODUCTION}

Narcissism has been described in a continuum that ranges from normal traits to pathological/ maladaptive forms (1). Studies demonstrate that most people can show narcissistic traits and behaviors; it claims that medium levels of narcissism can result in better functioning and more success (2). As a result, studying the trait narcissism (the subclinical form) is as vital as the pathological form (3). Various research indicate that trait narcissism predicts different types of psychological phenomena (4).

Research supports narcissism as a multidimensional construct (5). Many studies indicate that narcissism has at least two aspects: grandiosity (overt) and vulnerability (covert) (6). Grandiosity is characterized by attention-seeking, arrogance, lack of empathy, a remarkable sense of entitlement, fantasies of success, and high selfesteem; on the other hand, vulnerability is recognized with avoidance, egocentrism, feelings of inadequacy, and emotional vulnerability $(7,8)$. As a result, grandiose narcissists tend to be socially dominant, emotionally resilient, and antagonists, whereas vulnerable narcissists tangle with low self-esteem, attachment issues, and observable anxiety (9). A sense of superiority, dominance, and self-importance are some symptoms of grandiose narcissists (10). Most scholars consider grandiosity as the core feature of narcissism (11).

The relationship between grandiosity and vulnerability has been a matter of debate (12). First, recent modeling support that these two aspects share common associations with antagonism, entitlement, and egocentrism (13). On the other hand, studies support that narcissism can oscillate over time. A longitudinal study demonstrated that narcissism scores increased among undergraduate students over 25 years (14). In contrast, some other studies indicate no change in narcissism over time (15). Consequently, understanding the oscillations between grandiose and vulnerable aspects on the state-level narcissism is crucial for defining each dimension (16). Taken together, developing brief measures to assess the fluctuations between these two dimensions is a must to enable researchers to capture the oscillations in each state (17). 
The Narcissistic Grandiosity Scale (NGS) was first called the State-Trait Grandiosity Scale (18). This scale was originally developed by Rosenthal et al. and was presented at an academic conference in 2007 and was published later in 2019. However, it was used in various studies, supporting its suitable psychometric properties (19). NGS was developed to address the lack of a specific measure for assessing grandiosity for both trait (general aspects) and state (monetary aspects) levels (20). The NGS enables capturing one's internal feeling of superiority regardless of their intrapersonal attitudes of grandiosity and entitlement (21). It is an adjective-based and self-report scale consisting of 16 items and was modeled on the Positive and Negative Affect Scale (20).

The reliable and standard measures developed before NGS (e.g., NPI-16 (4)) required respondents to rate their agreement with general beliefs and images about themselves (e.g., I usually get the respect that I deserve) (22); these agreements were unlikely to change over time; considering that, an individual feeling Superior is more likely to oscillate as time passes by. Consequently, NGS brings the opportunity to capture what respondents feel at a particular time (13).

NGS captures a unidimensional construct distinguishable from self-esteem; research demonstrates satisfying psychometric properties (weighted mean $\alpha=.95$ ), strong convergent validity with NPI scores, and good discriminant validity (23). NGS is associated with low honesty and humility (24); it is also positively correlated with self-enhancement, unrealistic optimism (25), total scores of NPI (26), agreeableness and extraversion (27). Furthermore, NGS is a great tool to differentiate grandiosity from entitlement, exploitativeness, and high self-esteem (20).

Additionally, Crowe et al. (21) carried out a systematic validation for NGS via Ecological Momentary Assessment (EMA) studies. They conducted Additional item-level Item Response Theory (IRT) and compared a 13-item and 6-item version of NGS; the 13-item version had psychometric properties as good as the 16-item. Their proposed 6-item abbreviation has been recommended in various research as well (28). Using a different approach, Rosenthal et al. (20) identified a 7-item version of the scale. Furthermore, recent EMA designs support a 4-item set as the most suitable version (29). 
This research aims to examine the validity of NGS and propose the best-suited version (out of the five existing forms: NGS-16 and NGS-7 (20), NGS-13 and NGS-6 (21), and NGS-4 (29)) among Iranians.

\section{Materials and Methods}

\subsection{Procedures}

The NGS was adapted among Iranian samples in the following steps:

(1) first, we contacted Dr. Seth Rosenthal, the corresponding author of the original NGS study. We kindly requested and were granted permission to adopt this scale into Persian.

(2) then, the scale was translated forward into Persian and edited by six professionals in psychology.

(3) the finalized version was then translated back into English by an English Literature professional without any access to the original form. Then the original and translated version were compared and a few corrections were made for the item wordings and a final version was prepared. The translational procedure is depicted in Figure 1.

(4) Afterwards, we started a pilot study of 54 participants to investigate the reliability by calculating internal consistency coefficients for the general scale and subscales; 9 questionnaires were eliminated due to missing data. Forty-five sets remained for Cronbach's alpha.

(5) Then, we started the main sampling among 500 participants. Participants were administered the NGS, B-PNI, and RSES in their Persian translation. Demographic information including age, gender, education, the field of study, residency, and marital status was collected as well.

(6) Meanwhile, the NGS questionnaire was distributed among 55 participants for a test-retest study. With a two-week interval, participants were asked to fill in the questionnaire again. After a drop out of 5 participants, 50 people filled the questionnaire for the second time.

(7) The data were analyzed using descriptive statistics. Construct validity was tested via Confirmatory Factor Analysis (CFA) and Cronbach's alpha coefficient was used to evaluate the internal consistency. We assessed the test-retest reliability via Intra 
Class Coefficient (ICC). Pearson's correlations between the scores of Narcissistic Grandiosity Scale (NGS), Rosenberg Self-Esteem Scale (RSES), and Brief Pathological Narcissism Inventory subscales (B-PNI) were also investigated to assess concurrent and discriminant validity. SPSS 25 and $\mathrm{R}$ were utilized for all the psychometric analyses; we used the packages "lavaan" (Rosseel, 2012) (30) in R.

\subsection{Participants}

The translated forms of the questionnaires were distributed among 500 participants; 426 of them completed the full form. For the validation process, most studies suggest a sample of a minimum of 200-300 participants (31); Nunnally (32) also suggests a subject/ item ratio of 10/ 1 ratio as a suitable sample size meaning ten cases for each item. Assuming an estimated 20\% drop-out ratio, we need a minimum of 200 participants.

The sampling method was convenient sampling and forms were distributed via Instagram; participants were asked to fill an online form (which was prepared via the Porsline platform). The inclusion criteria were as follows: age older than 18 years, minimum college degree, and lack of cognitive problems. Not to mention that the Porsline platform only confirms submissions that have been fully answered; as a result, there was no missing data. Participants' ages ranged from 18 to 60 (59.6\% female). Confidentiality was granted and the written consent for their voluntary participation was obtained.

\subsection{Measures}

2.3.1. Narcissistic Grandiosity Scale (NGS): It is an adjective-based measure consisting of 16 items (like "envied", "superior", "extraordinary"). This measure is used to evaluate both trait (general narcissism traits) and state (current feelings) levels of grandiose narcissism. Participants were asked to describe each adjective "in general, that is, on the average" on a 7-point Likert scale from 1 (not at all) to 7 (extremely). The alpha coefficients ranged from 0.905 to 0.918 .

2.3.2. Rosenberg Self-Esteem Scale (RSES): This scale is developed by Rosenberg (1965)(33) to assess normative feelings of self-worth and was validated among Iranian samples by Beshlideh et al. (34). It consists of 10 
items; five of which demonstrate greater positive self-esteem (e.g., "I take a positive attitude toward myself"), and five items demonstrate greater negative self-esteem (e.g., "I wish I could have more respect for myself") rating from 0 (strongly disagree) to 4 (Strongly Agree) $(\alpha=0.808$ ). Negatively worded items were reverse coded (items 2, 5, 6, 8, \& 9); as a result, higher scores in RSES indicated higher self-esteem.

2.3.3. Brief Pathological Narcissism Inventory (B-PNI): The B-PNI is a selfreport measure (35) to assess two pathologic aspects of narcissism: Grandiosity and Vulnerability. The former is composed of Grandiose Fantasies (GF), Exploitativeness (EXPL), and Self-Sacrificing SelfEnhancement (SSSE) subscales; and Vulnerability consists of Contingent Self-Esteem (CSE), Devaluating (DEV), Entitlement Rage (ER), and Hiding the Self (HS) subscales (36). B-PNI has been validated among Iranian samples by Hasanzadeh, Akhani, \& Asgharnejad (37). The original questionnaire consists of 28 items; in the Persian version, one of the items for entitlement rage was removed due to its low internal consistency and it includes 27 items (like "I feel important when others rely on me" and "I often fantasize about being rewarded for my efforts"). Each of the seven subscales consists of four items (except for entitlement rage with three items). Each item is rated on a 6-point Likert scale from 0 (Not at all like me) to 5 (very much like me). Alphas ranged from .75 (Devaluation) to .826 (Exploitativeness).

\subsection{Ethical Consideration}

The NGS corresponding author was contacted to ask for their authorization for translating this questionnaire into Persian. Furthermore, confidentiality was granted to all participants via a written statement, and consent for their voluntary participation was obtained. Approval was also obtained from the Research Ethics Committee of School of Medicine, Tehran University of Medical Sciences (code number: IR.TUMS.MEDICINE.REC.1400.942). 


\section{RESULTS}

Among the 426 participants, $39.7 \%$ were between the ages of $18-28$ years, $44.4 \%$ were between 29-39, and the rest were above 40 years old; $59.6 \%$ were females, 49.3\% were married, 26\% had Diploma, and 65\% lived in Tehran (see Table 1).

Our study of psychometric properties consists of both reliability and validity. The degree to which the results are consistent with what we have been expecting is considered reliability which is based on stability and internal consistency (38). Validity indicates how great an instrument measures what it is supposed to measure (38). In this study, the content validity, divergent validity, and discriminant validity were assessed.

Table 1: Descriptive Statistics

\begin{tabular}{lllll}
\hline Variable & Category & Number & Percent & $\begin{array}{l}\text { Cumulative } \\
\text { Percentage }\end{array}$ \\
\hline Gender & Women & 254 & 59.6 & 59.6 \\
& Men & 172 & 40.4 & 100 \\
Marital & Single & 216 & 50.7 & 50.7 \\
Status & & & & \\
Age & Married & 210 & 49.3 & 100 \\
& $18-28$ & 169 & 39.7 & 39.7 \\
& $29-39$ & 189 & 44.4 & 84 \\
& $40-50$ & 62 & 14.6 & 98.6 \\
& $51-60$ & 6 & 1.4 & 100 \\
Education & Diploma & 111 & 26 & 26 \\
& Bachelor & 179 & 42 & 68 \\
& Master & 113 & 27 & 95 \\
& Ph.D. & 23 & 0.05 & 100 \\
Residence & Tehran & 278 & 65 & 65 \\
& Others & 148 & 35 & 100 \\
& & 426 & 100 & \\
\hline
\end{tabular}




\subsection{Translational Equivalence; Content and Face Validity}

We ran a qualitative assessment for face validity. With the help of six professionals, we used a forward-backward translation to verify the accuracy of the translation.

\subsection{Pilot Study}

We started the research with a pilot study of 54 participants ( 9 were removed due to missing data). All participants were asked to fill the paper-based questionnaires and mark the vague questions as well. Not to mention that incomplete questionnaires were removed from the study. Fortunately, no vague item was reported except for the HighStatus item which was unfilled by 4 participants; we added an extra meaning for this item in the original format. Cronbach's alpha was computed accordingly to make sure the research instrument was good. It was 0.909 for 45 participants.

\subsection{Confirmatory Factor Analysis}

Since there is an existing theory -which is warranted- behind this model and the data have been explored before in other research, in this study, we go directly to CFA. Furthermore, EFA has some serious limitations, while CFA provides better flexibility in modeling. First, EFA cannot address the correlated errors; for example, for questionnaires combined of both positive and reverse worded items (like RSES) (39). Second, EFA results for unidimensional questionnaires (as in NGS) tend to produce two factors solutions, though CFA brings the opportunity to specify a onefactor model, which results in a poor fit model. Third, recent research proposes that emotions are more bipolar (i.e., sadness and happiness represent the opposite sides of a single construct) than being independent (i.e., sadness and happiness are independent constructs). Early researches supported independence; as a result, EFAs typically demonstrate two-factor solutions for a single construct (39).

Although most SEM and CFA models use Maximum Likelihood (ML), studies demonstrate that ML is only suitable for multivariate normal and interval-type data and is robust to departures in normality (40). Since our data is non-normal, robust maximum likelihood (MLR) is a suggested method for CFA (40). 
A popular measure for assessing the model fit is the Chi-Square value and as Barrett (41) suggests, a good model fit has an non-significant result at a 0.05 threshold. Recently, Chi-Square has been considered an inappropriate measure (42) due to the impact of sample size on this measure. Wheaton et al. (43) propose a relative/normed chi-square $(\chi 2 / d f)$ as a suitable alternative, although there has been a dispute about the acceptable cutoff for it which ranges from as high as 5.0 (43) to as low as 2.0 (31). After all, Wheaton (43) suggests abounding this statistic. In this study, all the versions almost meet the cutoffs for the $\chi 2 / \mathrm{df}$ ratio.

Having more than three items typically incorporates linguistic heterogeneity, which causes ontological and causal heterogeneity. Accordingly, shorter versions are more recommended. As a result, we evaluated all versions fit indices. For further studies, we highly recommend that researchers implement the shorter version and replicate this study.

As shown, the 6-item model makes the most suitable model among Iranians. The indicators of absolute model fit RMSEA $=0.076$ meets the criteria (RMSEA $<=0.08$ ) (44), incremental indicators (CFI $>=0.95$, TLI $>=0.95)(45)$ and SRMR $(<=.05)$ (46), however values $<=0.08$ are deemed acceptable (45). The results among the five models proposed for NGS are demonstrated in Table 2.

Table 2: Fit indices for models in CFA

\begin{tabular}{|c|c|c|c|c|c|c|c|c|c|c|}
\hline \multirow[t]{2}{*}{ Model } & \multirow[t]{2}{*}{$\mathrm{X} 2$} & \multirow[t]{2}{*}{ df } & \multirow{2}{*}{$\begin{array}{c}\text { X2/ } \\
\text { df }\end{array}$} & \multirow[t]{2}{*}{$\mathbf{p}$} & \multirow{2}{*}{$\begin{array}{c}\text { RMSE } \\
\text { A }\end{array}$} & \multicolumn{2}{|c|}{ CI $90 \%$} & \multirow{2}{*}{$\begin{array}{c}\text { SRM } \\
\mathbf{R}\end{array}$} & \multirow[t]{2}{*}{ CFI } & \multirow[t]{2}{*}{ TLI } \\
\hline & & & & & & LO & HI & & & \\
\hline $\begin{array}{l}\text { 16- } \\
\text { item }\end{array}$ & $\begin{array}{l}416.77 \\
8\end{array}$ & 104 & 4.01 & $\begin{array}{l}0.00 \\
0\end{array}$ & 0.103 & $\begin{array}{l}0.09 \\
3\end{array}$ & $\begin{array}{l}0.11 \\
4\end{array}$ & 0.063 & $\begin{array}{l}0.85 \\
2\end{array}$ & 0.829 \\
\hline $\begin{array}{l}\text { 13- } \\
\text { item }\end{array}$ & $\begin{array}{l}206.49 \\
0\end{array}$ & 65 & 3.17 & $\begin{array}{l}0.00 \\
0\end{array}$ & 0.088 & $\begin{array}{l}0.07 \\
4\end{array}$ & $\begin{array}{l}0.10 \\
1\end{array}$ & 0.053 & $\begin{array}{l}0.90 \\
7\end{array}$ & 0.887 \\
\hline 6-item & 24.862 & 9 & 2.76 & $\begin{array}{l}\mathbf{0 . 0 0} \\
3\end{array}$ & 0.076 & $\begin{array}{l}0.04 \\
1\end{array}$ & $\begin{array}{l}0.11 \\
3\end{array}$ & 0.037 & $\begin{array}{l}0.97 \\
0\end{array}$ & 0.950 \\
\hline 7-item & 64.935 & 14 & 4.64 & $\begin{array}{l}0.00 \\
0\end{array}$ & 0.117 & $\begin{array}{l}0.08 \\
9\end{array}$ & $\begin{array}{l}0.14 \\
6\end{array}$ & 0.049 & $\begin{array}{l}0.92 \\
5\end{array}$ & 0.888 \\
\hline
\end{tabular}




\begin{tabular}{lllllllllll}
\hline 4-item & 12.411 & 2 & 6.20 & $\begin{array}{l}0.00 \\
2\end{array}$ & 0.116 & $\begin{array}{l}0.06 \\
0\end{array}$ & $\begin{array}{l}0.18 \\
2\end{array}$ & 0.037 & $\begin{array}{l}0.96 \\
5\end{array}$ & 0.896 \\
\hline
\end{tabular}

Note. 16-item (20), 13-item (21), 6-item (21), 7-item (20), 4-item (29), x2= chisquare; $\mathrm{df}=$ degree of freedom; $\mathrm{p}=$ probability; RMSEA= Root Mean Square Error of Approximation; $\mathrm{CI}=$ Confidence Interval; $\mathrm{SRMR}=$ Standardized Root Mean square Residual; CFI= Comparative Fit Index; TLI= Tucker- Lewis Index.

\subsection{Reliability}

Internal consistency was assessed using Cronbach's alpha. For the Cronbach's alpha, Nunnally (32) provided a lower cutoff (i.e., 0.70) and Lance et al. (47) proposed more stringent cutoffs like 0.90 or higher. For the NGS, Cronbach's alpha was 0.915 , and alphas for the items were in the range of 0.905-0.918 (Table 3). The test-retest reliability coefficient was $0.904(\mathrm{~N}=50, \mathrm{P}<0.01)$.

Table 3: Cronbach's alpha coefficients for NGS

\begin{tabular}{lllllll}
\hline & $\begin{array}{l}\mathbf{1 6} \\
\text { items } \\
\text { Mean }\end{array}$ & $\begin{array}{l}\text { alpha if } \\
\text { Item } \\
\text { Deleted }\end{array}$ & $\begin{array}{l}\mathbf{1 3} \\
\text { items }\end{array}$ & $\begin{array}{l}\mathbf{6} \\
\text { items }\end{array}$ & $\begin{array}{l}\mathbf{7} \\
\text { items }\end{array}$ & $\begin{array}{l}\mathbf{4} \\
\text { items }\end{array}$ \\
\hline 1. Acclaimed & 67.73 & .912 & $\mathrm{X}$ & $\mathrm{X}$ & & \\
2. & 68.01 & .911 & $\mathrm{X}$ & & $\mathrm{X}$ & \\
Authoritative & & & & & & \\
3. Brilliant & 67.21 & .912 & & & & $\mathrm{X}$ \\
4. Dominant & 68.25 & .909 & $\mathrm{X}$ & & $\mathrm{X}$ & \\
5. Envied & 68.35 & .918 & $\mathrm{X}$ & & $\mathrm{X}$ & \\
6. & 68.60 & .908 & & & & \\
Extraordinary & & & & & & \\
7. Glorious & 68.19 & .906 & $\mathrm{X}$ & $\mathrm{X}$ & & $\mathrm{X}$ \\
8. Heroic & 67.96 & .910 & $\mathrm{X}$ & & & \\
9. High-status & 68.72 & .906 & $\mathrm{X}$ & $\mathrm{X}$ & $\mathrm{X}$ & \\
10. & 68.44 & .907 & $\mathrm{X}$ & & & \\
Omnipotent & & & & & & \\
\hline
\end{tabular}




\begin{tabular}{lcccccc}
\hline 11. Perfect & 69.86 & .909 & $\mathrm{X}$ & & & \\
12. Powerful & 68.50 & .905 & $\mathrm{X}$ & $\mathrm{X}$ & $\mathrm{X}$ & $\mathrm{X}$ \\
13. & 66.93 & .916 & $\mathrm{X}$ & $\mathrm{X}$ & & $\mathrm{X}$ \\
Prestigious & & & & & & \\
14. Prominent & 68.65 & .909 & $\mathrm{X}$ & $\mathrm{X}$ & $\mathrm{X}$ & \\
15. Superior & 68.80 & .906 & $\mathrm{X}$ & & $\mathrm{X}$ & \\
16. Unrivaled & 69.52 & .908 & & & & \\
alpha & & 0.914 & 0.896 & 0.806 & 0.840 & 0.703 \\
\hline
\end{tabular}

Note. The items for each version are marked by $\mathrm{X}$.

\subsection{Convergent and Discriminant Validity}

As proposed by Cronbach and Meehl, construct validity should be evaluated by the correlations between the specific scale with other recognized questionnaires measuring the same construct (48). To this end, we implemented a convergent validity via assessing the Pearson correlation coefficients between the total score of NGS, RSES, and the grandiosity subscale of B-PNI. Furthermore, the divergent (discriminant) validity was evaluated through the Pearson correlation with vulnerability subscale of B-PNI. The results are presented in Table 4, not to mention that all calculations were conducted for all five versions.

According to Kline (49), correlations close to or above 0.7 are an acceptable threshold for convergent validity. As shown in Table 4, the Narcissistic Grandiosity Scale has a significant and positive relationship with self-esteem and a small positive correlation with the grandiosity subscale. On the other hand, NGS has a negative relationship with vulnerability proposing discriminant validity with this construct. These results are consistent with previous research (20).

Table 4: Means, Standard Deviations, and Scale Intercorrelation between NGS, $B$-PNI subscales (vulnerability, grandiosity), and RSES (self-esteem)

\begin{tabular}{lllll}
\hline $\begin{array}{l}\text { Variab } \\
\text { le }\end{array}$ & Mean (SD) & RSES & Gran & Vul \\
\hline 16 -item & $72.92(17.63)$ & $0.562^{* *}$ & $\begin{array}{l}0.235^{*} \\
*\end{array}$ & $-0.110^{*}$ \\
& & & & \\
\hline
\end{tabular}




\begin{tabular}{|c|c|c|c|c|}
\hline 13-item & $59.50(14.57)$ & $0.560 * *$ & $\begin{array}{l}0.227 * \\
*\end{array}$ & $-0.117 *$ \\
\hline 6-item & $28.76(6.82)$ & $0.568 * *$ & $\begin{array}{l}0.200 * \\
*\end{array}$ & $\begin{array}{l}- \\
0.127 * *\end{array}$ \\
\hline 7-item & $31.12(8.62)$ & $0.506^{* *}$ & $\begin{array}{l}0.235^{*} \\
*\end{array}$ & -0.091 \\
\hline 4-item & $20.82(4.24)$ & $0.543 * *$ & $\begin{array}{l}0.195 * \\
*\end{array}$ & $\begin{array}{l}- \\
0.146^{* * *}\end{array}$ \\
\hline
\end{tabular}

Note. Pearson coefficients between NGS: Narcissistic Grandiosity Scale, RSES: Rosenberg Self-Esteem Scale RSES, Gran: Grandiosity subscale of B-PNI, and Vul: Vulnerability subscale of B-PNI.

$* \mathrm{p}<.05, * * \mathrm{p}<.01$ (two-tailed).

4. Discussion

The present study aimed to examine the psychometric properties of the Persian version of the NGS for measuring the momentary and dispositional manifestations of grandiose narcissism among Iranians. The results demonstrated that the 16-item version does not have an idea model fit; on the other hand, the 6-item version proposes an adequate validity and reliability of the questionnaire among Iranians.

Along with the increasing interest in assessing the fluctuations of different types of narcissism, NGS is a promising scale due to the following reasons: First and foremost, current measures can only assess narcissism on a trait level and can assess what individuals feel in general and not at the moment whereas NGS can evaluate one's narcissistic attitudes for both "in general" and "momentary" levels. Secondly, NGS provides the opportunity to examine the oscillations between grandiosity and vulnerability as time passes by. Last but not least, NGS is a short questionnaire that can be completed in less than two minutes. As a result, the necessity of validating this questionnaire among Iranians seems inarguable.

This study focused on the content and face validity procedures to have the most suitable translation. NGS was investigated for validity (face, content, and convergent) and reliability (internal consistency, test-retest, and confirmatory factor 
analysis). The results support this measure's adequate validity and reliability among Iranian samples for the 6-item version.

Qualitative methods were carried out to investigate content validity. Additionally, we evaluated the face validity with the help of six professionals. Then we implemented a pilot study with 54 Participants to investigate the internal consistency and whether there is any vague translation. The Cronbach Alpha was 0.909. Moreover, no vague item was reported by the participants. Consequently, we started the main study.

As discussed in the introduction section, since the initial development of NGS by Rosenthal (50), the items went through four abbreviations that apply perfectly in modern life. As a result, we evaluated confirmatory factor analysis for all five existing versions. Results demonstrate that the 6 -item version fits the best among the other four versions $(\mathrm{RMSEA}=0.076, \mathrm{SRMR}=0.037, \mathrm{CFI}=0.970$, and $\mathrm{TLI}=0.950$ ). Cronbach's alpha of 0.914 was found for the NGS full version, supporting a good internal consistency. The test-retest reliability coefficient was 0.904 .

Furthermore, convergent validity was established with the NGS's correlations with RSES and the grandiosity subscale of B-PNI and were 0.562 and 0.235 , respectively. The Pearson correlation between NGS and vulnerability subscale of B-PNI was also carried out for discriminant validity and was -0.110 . The findings are consistent with other studies conducted in the US (51) and Netherlands (52).

\section{Limitation}

Validating an instrument in another language can tangle with a few challenges; for instance, the adjective-based measures can be culturally specific. Emotions, in some cases, are not cross-culturally invariant, and Iranian people from a collectivist culture can report these emotions in an incomparable way from individualistic cultures. Even though this measure is adjective-based and adjective can be crossculturally invariant, the procedure implemented for the translational equivalence was pretty intense; it also benefited from various insightful feedback from narcissism and statistical experts. Furthermore, it is the first scale to assess narcissism at both state and trait levels translated into Persian. Researchers can implement this instrument for their future research assessing the oscillations of grandiosity over time.

\section{Conclusion}


Recent studies support newer models depicting narcissism at both trait and state levels that can fluctuate over time. The studies indicate that grandiosity and vulnerability share some core features and differ in certain factors. Although the older instruments cannot measure the recent definition of narcissism, it has been a while that better instruments have been developed to assess aspects of narcissism based on these models. Unfortunately, in Iran, there is a dramatic gap to access to new culturally variant instruments. In this study, we evaluated the psychometric properties of the Persian version of NGS for future researchers to conduct newer models.

Based on our findings, we suggest the following. First, due to the fit indices for various versions, we recommend researchers replicate the studies with short versions such as the 6-item version. Second, since we did not have access to random sampling, we highly recommend using different samples to check whether each model fits best.

\section{Credit authorship contribution statement}

Sara Hoseingholizade: Conceptualization, project administration, data collection, conducting methodology and data analysis, writing, and editing. Mohammad Effatpanah \& Ali Mohammad Mousavi: Supervision and editing. Nazanin Mousavi: Data collection and bibliography. Mandana Piryaei: Data collection.

\section{Declaration of Interests}

The authors declare that is no conflict of interest in this study.

\section{Acknowledgment}

The authors wish to thank Dr. Seth Rosenthal and Dr. Michael Crowe for providing the instrument and their helpful comments. We would like to thank Dr. Amin Mousavi for his insightful comments as well. The authors are also grateful to all the 
participants who put their time voluntarily into this research. No funding was received for this study.

\section{REFERENCES}

1. Blais MA, Little JA. Toward an integrative study of narcissism. 2010.

2. de Vries MFK, Miller D. Narcissism and leadership: An object relations perspective. Human Relations. 1985;38(6):583-601.

3. Paulhus DL. Normal narcissism: Two minimalist accounts. Psychological Inquiry. 2001;12(4):228-30.

4. Ames DR, Rose P, Anderson CP. The NPI-16 as a short measure of narcissism. Journal of research in personality. 2006;40(4):440-50.

5. Cain NM, Pincus AL, Ansell EB. Narcissism at the crossroads: Phenotypic description of pathological narcissism across clinical theory, social/personality psychology, and psychiatric diagnosis. Clinical psychology review. 2008;28(4):638-56.

6. Campbell WK, Miller JD. The handbook of narcissism and narcissistic personality disorder: Wiley Online Library; 2011.

7. Miller JD, Lynam DR, Hyatt CS, Campbell WK. Controversies in narcissism. Annual review of clinical psychology. 2017;13:291-315.

8. Wright AG, Edershile EA. Issues resolved and unresolved in pathological narcissism. Current Opinion in Psychology. 2018;21:74-9.

9. Miller JD, Lynam DR, Hyatt CS, Campbell WK. Controversies in Narcissism. Annual Review of Clinical Psychology. 2017;13(1):291-315.

10. Tracy JL, Cheng JT, Robins RW, Trzesniewski KH. Authentic and hubristic pride: The affective core of self-esteem and narcissism. Self and identity. 2009;8(2-3):196-213.

11. Ackerman RA, Hands AJ, Donnellan MB, Hopwood CJ, Witt EA. Experts' views regarding the conceptualization of narcissism. Journal of personality disorders. 2017;31(3):346-61.

12. Miller JD, Hoffman BJ, Gaughan ET, Gentile B, Maples J, Keith Campbell W. Grandiose and vulnerable narcissism: A nomological network analysis. Journal of personality. 2011;79(5):1013-42. 
13. Crowe ML, Lynam DR, Campbell WK, Miller JD. Exploring the structure of narcissism: Toward an integrated solution. Journal of Personality. 2019;87(6):1151-69.

14. Twenge JM, Konrath S, Foster JD, Campbell WK, Bushman BJ. Further evidence of an increase in narcissism among college students. Journal of Personality. 2008;76(4):919-28.

15. Trzesniewski KH, Donnellan MB, Robins RW. Is "Generation Me" really more narcissistic than previous generations? Journal of Personality. 2008;76(4):903-18.

16. Pincus AL, Ansell EB, Pimentel CA, Cain NM, Wright AG, Levy KN. Initial construction and validation of the Pathological Narcissism Inventory. Psychological assessment. 2009;21(3):365.

17. Edershile EA, Wright AG. Fluctuations in grandiose and vulnerable narcissistic states: A momentary perspective. Journal of Personality and Social Psychology. 2020.

18. Rosenthal SA. The fine line between confidence and arrogance: Investigating the relationship of self-esteem to narcissism: Harvard University; 2005.

19. Brown RP, Budzek K, Tamborski M. On the meaning and measure of narcissism. Personality and Social Psychology Bulletin. 2009;35(7):951-64.

20. Rosenthal SA, Hooley JM, Montoya RM, van der Linden SL, Steshenko Y. The Narcissistic Grandiosity Scale: A measure to distinguish narcissistic grandiosity from high self-esteem. Assessment. 2020;27(3):487-507.

21. Crowe ML, LoPilato AC, Campbell WK, Miller JD. Identifying two groups of entitled individuals: Cluster analysis reveals emotional stability and self-esteem distinction. Journal of personality disorders. 2016;30(6):762-75.

22. Giacomin $\mathrm{M}$, Jordan $\mathrm{CH}$. Validating power makes communal narcissists less communal. Self and Identity. 2015;14(5):583-601.

23. Nunnally JC. Psychometric theory. New York: McGraw-Hill; 1978.

24. Watts AL, Waldman ID, Smith SF, Poore HE, Lilienfeld SO. The nature and correlates of the dark triad: The answers depend on the questions. Journal of Abnormal Psychology. 2017;126(7):951.

25. Tamborski M, Brown RP, Chowning K. Self-serving bias or simply serving the self? Evidence for a dimensional approach to narcissism. Personality and individual differences. 2012;52(8):942-6. 
26. Gentile B, Miller JD, Hoffman BJ, Reidy DE, Zeichner A, Campbell WK. A test of two brief measures of grandiose narcissism: The Narcissistic Personality Inventory-13 and the Narcissistic Personality Inventory-16. Psychological assessment. 2013;25(4):1120.

27. Miller JD, Price J, Gentile B, Lynam DR, Campbell WK. Grandiose and vulnerable narcissism from the perspective of the interpersonal circumplex. Personality and individual differences. 2012;53(4):507-12.

28. Foster JD, Brantley JA, Kern ML, Kotze J-L, Slagel BA, Szabo K. The many measures of grandiose narcissism. Handbook of Trait Narcissism: Springer; 2018. p. 115-23.

29. Edershile EA, Woods WC, Sharpe BM, Crowe ML, Miller JD, Wright AG. A day in the life of Narcissus: Measuring narcissistic grandiosity and vulnerability in daily life. Psychological Assessment. 2019;31(7):913.

30. Rosseel Y. Lavaan: An R package for structural equation modeling and more. Version 0.5-12 (BETA). Journal of statistical software. 2012;48(2):1-36.

31. Tabachnick BG, Fidell LS. Using multivariate statistics. Boston: Pearson Education; 2013.

32. Nunnally JC. Psychometric Theory 2nd ed. Mcgraw hill book company; 1978.

33. Rosenberg M. Rosenberg self-esteem scale (RSE). Acceptance and commitment therapy Measures package. 1965;61(52):18.

34. Beshlideh K, Yousefi N, Haghighi J, Behrouzi N. An Investigation of Psycho-Metric Properties of Rosenberg Self-Esteem Scale in Students of Shahid Chamran University in Ahwaz. 2012.

35. Schoenleber M, Roche MJ, Wetzel E, Pincus AL, Roberts BW. Development of a brief version of the Pathological Narcissism Inventory. Psychological assessment. 2015;27(4):1520.

36. Wright AG, Lukowitsky MR, Pincus AL, Conroy DE. The higher order factor structure and gender invariance of the Pathological Narcissism Inventory. Assessment. 2010;17(4):467-83.

37. Hassanzadeh F, Akhani A, Asgharnejad Farid A. Psychometric Properties of Brief Version of Pathological Narcissism Inventory. J Neyshabur Univ Med Sci. 2020;8(1):77-87.

38. García de Yébenes Prous M, Rodríguez Salvanés F, Carmona Ortells L. Validación de cuestionarios. Reumatología clínica. 2009;5(4):171-7. 
39. Brown TA. Confirmatory factor analysis for applied research: New York : Guilford Press, [2006] ()2006; 2006.

40. Bentler PM. EQS structural equations program manual. Encino, Calif.: Multivariate Software; 1995.

41. Barrett P. Structural equation modelling: Adjudging model fit. Personality and Individual differences. 2007;42(5):815-24.

42. Kline RB. Principles and practice of structural equation modelling. New York. Guilford Press. 2005;10:1049731509336986.

43. Wheaton B, Muthen B, Alwin DF, Summers GF. Assessing reliability and stability in panel models. Sociological methodology. 1977;8:84-136.

44. MacCallum RC, Browne MW, Sugawara HM. Power analysis and determination of sample size for covariance structure modeling. Psychological methods. 1996;1(2):130.

45. Hu Lt, Bentler PM. Cutoff criteria for fit indexes in covariance structure analysis: Conventional criteria versus new alternatives. Structural equation modeling: a multidisciplinary journal. 1999;6(1):1-55.

46. Diamantopoulos A, Siguaw JA, Siguaw JA. Introducing LISREL: A guide for the uninitiated: Sage; 2000.

47. Lance CE, Butts MM, Michels LC. The sources of four commonly reported cutoff criteria: What did they really say? Organizational research methods. 2006;9(2):202-20.

48. Guion RM, Cranny CJ. A note on concurrent and predictive validity designs: A critical reanalysis. 1982.

49. Kline TJ, Sulsky LM, Rever-Moriyama SD. Common method variance and specification errors: A practical approach to detection. The Journal of psychology. 2000;134(4):401-21.

50. Rosenthal S, Hooley J, Steshenko Y. Distinguishing grandiosity from selfesteem: Development of the Narcissistic Grandiosity Scale. Manuscript in preparation. 2007.

51. Rosenthal SA, Pittinsky TL. Narcissistic leadership. The leadership quarterly. 2006;17(6):617-33.

52. Brummelman E, Thomaes S, Sedikides C. Separating narcissism from selfesteem. Current Directions in Psychological Science. 2016;25(1):8-13. 
